\title{
Nursing students' experiences during a rural community placement programme in Namibia - 2001
}

\author{
SN lipinge, D Cur, Department of Nursing Science, University of Namibia \\ ES Venter, M Soc Sc, Department of Nursing Science, University of Namibia
}

\section{Abstract}

The reviewed nursing curriculum in Namibia incorporated issues related to Primary Health Care and diversification in the practical field for student nurses. This means that the students are exposed more to their communities than before. Nurses identify, manage and refer, if need be, the problems at this level. The curriculum facilitates and strengthens problem-solving skills and enhances the ability of nurses to adapt a comprehensive and family centred approach.

The aim of this article is to describe the process of the rural placement of nursing students and to describe the experiences of the students as derived from the placement programme in districts in the central health directorate. Both positive and negative experiences are described. It is clear that the students have gained selfconfidence in problem management. This article further confirms that learning experiences in the community setting is comparable to the hospital and other clinical learning settings in facilitating student's personal and academic development.

\section{Abstrak}

Die hersiene verpleegkurrikulum in Namibia sluit aspekte in wat verband hou met primêre gesondheid sorg, sowel as 'n diversifisering in die praktiese veld vir studentverpleegsters. Dit beteken dat studente meer blootgestel word aan plattelandse gemeenskappe as voorheen. Hulle identifiseer, hanteer en verwys gesondheidsprobleme op die vlak van gesondheidsdienslewering. Die kurrikulum is gerig om probleemoplossings vaardighede te fasiliteer en te versterk. Dit bied verder geleenthede om ' $n$ omvattende en gesinsentreerde benadering te ontwikkel.

Die doel van hierdie artikel is om die proses van die plasing van studente in die platteland, sowel as die ervarings daarvan, soos deur die studente self beskryf, te bespreek. Beide postitiewe en negatiewe ervarings word beskryf. Dit is duidelik dat die studente gebaat het ten opsigte van die verkryging van selfvertroue, veral met betrekking tot probleemhantering. Hierdie artikel bevestig dat die leergeleenthede in die plattelandse gemeenskapsomgewing vergelykbaar is met die van die hospitaal en ander kliniese leeromgewings, om studente se persoonlike en akademiese ontwikkeling te fasiliteer.

\section{Background and orientation}

With Independence of Namibia in 1990, the Government has adopted primary health care as strategy to provide care to the population in Namibia at a cost the community and the country can afford. The Ministry of Health and Social Service's health policy is based on the principles of equity, accessibility, availability, affordability and cost sharing. All people are regarded as equal citizens and freedom of choice is guaranteed. The whole system of service provision was reviewed and reoriented towards primary health care and the majority of health workers were retrained and reoriented towards primary health care.

Changes in the health care delivery system lead to the shift- ing of health priorities and the restructuring of alliances in the health sector. This resulted in situations where nurse practitioner's workplace and roles changed substantially. Clients are increasingly found outside acute care centres, in their residences and in community settings (Oneha, Magnussen \& Feletti, 1998:26). In a changed health care system this is of importance for nurses to learn to communicate well, think critically and make informed, independent decisions.

In accordance with the policy of the Ministry of Health and Social Services, the curriculum of nurses was therefore reviewed, and issues related to primary health care were incorporated. It was also necessary to diversify the learning environment for student nurses. The revised curriculum of the University Diploma in Comprehensive Nursing and 
Midwifery Science emphasises self-directed learning and resourcefulness, while the demonstration of proficiency in a wide range of clinical nursing skills remains an important aspect. Additionally to this, nurses need to demonstrate cultural sensitivity and diverse healing practices to enhance the client's compliance in self-management.

The revised curriculum has been implemented in 1996 and made provision for nursing students to spend more time in the communities and spend less time at urban health facilities. Noorman (1994:69) describes community placements as "a curriculum that throughout its entire duration includes an appropriate proportion of learning activities in a balanced variety of educational settings in the community and in a diversity of health care services at all levels". A rural community placement programme was developed within the curriculum, exposing nursing students in their final year of study to different communities in Namibia.

This rural community placement programme aims to provide the student nurse with a setting in which appropriate knowledge, effective skills and positive attitudes to practice nursing competently within a multi-cultural context, can develop. The following objectives guide the student nurse throughout his/her practice. It is expected from him/ her to:

- $\quad$ assess community/family and individual needs and health problems.

- $\quad$ provide preventive and promotive nursing and midwifery care that responds to the health needs of the community.

- $\quad$ use the techniques of problem solving in addressing identified needs/problems in the community.

- $\quad$ plan and manage health resources effectively and efficiently.

- $\quad$ initiate and facilitate education for the community, family and individual. through effective communicative and inter-personal skills according to needs.

- strengthen the independent practice of the student.

- $\quad$ practice nursing and midwifery within a multi-cultural context.

- $\quad$ complete their practical workbook.

The World Health Organisation (WHO, 1985:87) viewed education within a community setting as "a means to ensuring that health personnel are responsive to the health needs of the people and a means of achieving educational relevance to community needs". The rural community placement programme is thus seen as an educational programme with the main focus of the student's learning activities of promoting health and preventing illness within the community.

\section{The rationale and justification of the programme}

The nursing profession and clinical learning 'per se', has been associated with hospitals and other similar situations for a very long time, but Dana and Gwele (1998:59) argue that health needs of communities are not addressed adequately by traditional clinical learning sites such as hospital wards. They further indicate that the hospital is no longer seen as the most appropriate clinical learning environment for preparing professional nurses. The future role of the nurse is one of being an agent, preparing clients to assume responsibility for their own health and self-care.

By actually living and practising in a rural community, students learn that rural health care presents unique challenges as well as opportunities for a positive, quality lifestyle, both personally and professionally (Erkel, Nivens and Kennedy, 1995:359).

The community is seen as a reality and coming to terms with reality is the necessary prerequisite for learning. Increased opportunities to gain experience in practical procedures, techniques and communicating with patients and clients as well as the importance to the acquisition of confidence should be one of the outcome goals of such a rural placement programme. Students are expected to be selfdirecting, but they need some supervision, guidance and support with managing their learning activities.

The community is therefore gaining popularity as a clinical learning environment within the training context of the Namibian nurse, emphasising Primary Health Care. However, the experiences of the student nurse of the rural community placement programme as a learning opportunity, have not been fully explored.

That lead to the question asked by the authors: 'How did the student nurse experience the rural community placement programme?"

\section{Objectives of the article}

The objectives of the article were threefold.

Firstly to describe the process of the rural community placement programme. Secondly to describe student nurses' experiences during the rural community placement programme, and lastly, to describe suggestions that may guide the future planning of rural community placement programmes.

\section{The rural placement programme: the process}

The Namibian health care system is divided into 4 health directorates namely South, Central, North West and North East, all these directorates are responsible to the Director of Primary Health Care.

To facilitate the process, exploratory field trips and consultations were undertaken by the authors (both lecturers at the University of Namibia).

Phase 1: Discussions were held with the Director of Pri- 
mary Health Care, the Head of the Nursing Division and the Deputy-Secretary of Health. These discussions explored the possible districts to place students, the transport and accommodation arrangements as well as the supervision of the students. The three officers were supportive and excited about the programme. They identified the Central Health Directorate as a suitable area to start with. The reasons were that its outreach programmes are in place and the nurses and medical officers would be able to provide appropriate supervision because they also deal with the training of pupil nurses. The Ministry of Health and Social Services would provide the accommodation, but the University of Namibia would provide transport. The Ministry, however, was prepared to provide transport for students during their stay in the region, when moving between health facilities.

Phase 2: Field trips were undertaken to Otjiwarongo, Grootfontein, Okakarara and Khorixas by the lecturers(authors) to familiarise themselves of the situation in the area and also to meet the prospective supervisors (i.e. registered nurses at health facility levels), who are registered nurses employed by the Minister of Health and Social Services. The objectives of the programme and the practical workbook was explained and discussed with them. Focal persons were identified in each district. The duration of a placement would be two months. On return, feedback was given to both students and other faculty members. All the stakeholders were supportive to the programme.

During the 2 months of placement, two of the student's lecturers visited the students twice. During such visits, the students and supervisors (i.e. the registered nurses under whose students were working daily) in the field gave feedback. The supervisors, at health facility levels, expressed a feeling of uncertainty of dealing with the student nurses, as this was the first time such an exercise was launched in the rural health communities.

Practical evaluation of the students were also done while visiting them. Field notes were taken of the feedback that given by the students and are included in this report.

\section{Student nurses' experiences during the placement programme}

A descriptive- explorative-contextual design with a qualitative approach was utilised (Burns and Grove, 1997:2829). The nurses were asked to describe his/her experiences during the rural community placement programme. This method was used to collect data regarding the nurse's experiences but also to ascribe meaning and understanding to these experiences. This method was chosen because nurses were placed in various communities, regardless of their language and culture. The descriptions provided data on what these nurses experienced from working in the different rural communities.

\section{- Sample}

The population consisted of 23 final year student nurses registered for the course, University Diploma in Compre- hensive Nursing and Midwifery Science. A purposive sample of 23 nurses (Burns and Grove, 1997:306) was utilised. The descriptions of all the nurses were used to gain insight into the area of research.

\section{- Measures for ensuring trustworthiness}

In this research measures for ensuring trustworthiness were based on the model of Guba (in Lincoln and Guba, 1985:289331), measuring truth-value, applicability, consistency and neutrality.

\section{- Data collection}

Data was collected through written descriptions given by the nurses as respondents. All respondents who were part of the rural community placement programme, were requested to complete a written description on how they experienced the rural community placement programme. A total of 23 student nurses completed these descriptions.

The field notes made by the authors during the visits to the rural communities where the student nurses have been placed, form part of the data collected.

\section{- Data analysis}

Two coders did the data analysis independently. A protocol describing the method of data analysis was developed, based on the approach proposes by Tesch (in Creswell, 1994:155) for open coding.

\section{- Literature control}

A literature control with other similar research was conducted to verify the results of this research (Morse and Field, 1996:103-107).

\section{Student nurses' experiences}

From the analysis of the results, the following themes were identified:

- Positive experiences of the students

- Negative experiences of the students

Data will be supported by means of direct quotes of respondents as well as a literature control in order to recontextualise data. (Morse and Field, 1996:103-107).

Following a discussion of the main themes and sub themes.

\section{Positive Experiences}

It appeared as though most of the students described their experiences as useful to their development as independent nurse practitioners. Feelings of appreciation, acceptance and self-fulfilment were expressed. These feelings where highlighted as part of personal development, during experiences of delivery of health care and during community based health activities. Sub-themes emerged where the respondents described the development of confidence, the acceptance of responsibility for their own actions as well as feelings of satisfaction while dealing with health personnel, clients and families within the community setting 


\begin{tabular}{|c|c|}
\hline CREDIBILTY & \\
\hline Prolonged engagement & $\begin{array}{l}\text { *Researchers (authors) are experienced in community based training. } \\
\text { * Researchers visited the fields twice, prior to placement of students and } \\
\text { * Researchers also visited the field three times during their placement }\end{array}$ \\
\hline Triangulation & $\begin{array}{l}\text { * All students participate in research. } \\
{ }^{*} \text { Literature control was conducted to verify results of research. }\end{array}$ \\
\hline Peer debriefing & $\begin{array}{l}\text { * Colleagues and researchers familiar with community based education. } \\
\text { * Literature control - experiences regarding community based education vs. hos- } \\
\text { pital-based education. } \\
\text { * discussion with faculty members of the report on rural placement }\end{array}$ \\
\hline Member checking & * Students reviewed and validated research interpretations and conclusions. \\
\hline \multicolumn{2}{|l|}{ TRANSFERABILITY } \\
\hline $\begin{array}{l}\text { Dense description of } \\
\text { methodology }\end{array}$ & * Research methodology clearly and fully described. \\
\hline \multicolumn{2}{|l|}{ DEPENDABILTY } \\
\hline Dependability audit & $\begin{array}{l}\text { * Data analysis protocol developed. } \\
\text { * Independent data coder used. } \\
\text { * Literature control done. }\end{array}$ \\
\hline \multicolumn{2}{|l|}{ CONFIRMABILITY } \\
\hline $\begin{array}{l}\text { Observation periods spaced } \\
\text { throughout the placement } \\
\text { programme. }\end{array}$ & * Visits to rural communities by researchers. \\
\hline Triangulation & * As discussed. \\
\hline Reflexivity & $\begin{array}{l}\text { * Consensus among researchers and discussions with independent coder. } \\
\text { * Taking of field notes during visits by researchers. }\end{array}$ \\
\hline
\end{tabular}

\section{- Self development}

\section{Confidence and responsibility}

The majority of students experienced the rural placement as a challenge to developing self-confidence and responsibility within the work situation. As students stated "I learned to be responsible and accountable because there I handled different and complicated cases". "This helped me not only to developed responsibility, independence and self-confidence, but also to be able to manage cases on my own".

It seems as if the exposure of working independently boosted confidence in decision making abilities and knowledge regarding health matters. One response was: "We happen to work many times alone ... which I thought was a very difficult thing I could ever do in my life. But it wasn't, because I was exposed to different conditions and I developed much confidence and responsibility". Another stated:"... the rural placement made a big difference in my knowledge and understanding of health problems". Some students also believed their interpersonal skills improved. One said the exposure "gave a greater room of learning in terms of clinical practice and allows the improvement of skills", while another commented "I felt great because I gave counselling which required me to display those skills".

\section{Work satisfaction}

Most of the students indicated a sense of satisfaction while working in the rural areas. They indicated that satisfaction did not only lie in the taking of charge of a health clinic but also in the socialisation with acceptance of health personnel and the community. As one student stated: “...this makes me full of self confidence and I was proud of myself being at this point, solving problem cases and being trusted by my sister as well as my clients".

Being trusted and accepted as a member of the health team 
contributed to the feelings of satisfaction. The students described their feelings as follows: "I was encouraged that the nurses and even the doctor had confidence in us students - this motivated us and ensures a feeling of being-incontrol". "I felt a sense of freedom and feeling at home because of the trust between staff members", and "I feel proud to be part of the nursing profession".

The written descriptions of the students, reflecting on selfdevelopment during the rural placement evolved from their experiences within the health centres and the immediate community they served. An important element of this rural placement exercise was to place nursing students in learning environments that more closely reflect future professional practice settings. (Oneha, Magnussen \& Feletti 1998: 28). Clinical placement in rural community settings can provide nursing students with valuable opportunities to understand health-related problems as perceived by the community. As indicated by Smith (1999:46), students are often not confronted with new foundational concepts, but their confidence in their ability to apply them with more depth in a rural community health care setting, increases. Additionally students frequently comment that they have a broader perspective on professional practice roles and more confidence in their ability to function independently as a professional and collaboratively as a team member.

\section{- Health care delivery Health assessment}

It became apparent that the students abilities to assess and manage health problems of clients, where thoroughly put to the practice. As one student stated: "We worked closely with the clients for 2 weeks and that improved much on our history taking, making of nursing diagnosis". Another one added: "We refer patients to the doctor, decide on nursing diagnosis and prescribed treatment. We also had time to give proper health education". Involvement with the client and his/her family during assessment often proved to be satisfactory, as stated by one student: "I have learned to sympathise with those in pain".

They were exposed to different disease conditions that are prevalent to that specific area and learned about treatment and dosages. The students comment as follows:

"I was so exposed to different kinds of diseases which some I never saw in my life".

"Now I understand the prescription of drugs, dose, effects and side effect better". Another stated, "I have learned much about malaria, HIV/AIDS, pneumonia and bronchitis".

A number of students partook in emergency cases, and responded as such: "We were alone, running the clinic after hours, receiving calls and attending emergencies". "I handled different and complicated cases like hypertensive crisis, asthma attacks, and rescue patient from a car accident, post partum haemorrhage, epileptic fits and cardiac arrest. I managed these cases with the help of the registered nurse".

\section{Strengthening of managerial skills}

All students reported that they were involved in aspects of an administrative or managerial nature. One student stated that: I have learned a lot about the management of clients, doing delegation of all staff. Others mentioned the following:

"A good experience was that I learned the goodness of saving antibiotics and keeping in stock the life saving drugs because I used them in reality".

"Exercise taught me to improvise due to limited resources in the rural area".

The management of health programmes in the health centre, is based on the existing national policies and the respondents described their experiences in this regard as follows: "The registered nurse in charge showed us the different policies and explained the day-to-day programme of the clinic". The students were involved in all the services rendered at the health centres.

\section{Involvement in the health team}

The independent nurse practitioner should participate within team context. The majority of students' comments were positive in this regard. A student commented: "Teamwork was also a good experience, even assistant nurses were good to everybody and they were not discriminated against, everybody was treated equal and it gives a good working environment". Another mentioned that "We use to have in-service training conducted by the doctors and we had the opportunity of choosing topics to be discussed any time".

It is worthwhile mentioning that the students were also engaged in educating the registered nurses on aspects required by them, as stated by one student: "The registered nurses were also humble enough to ask us things they believed we know and they don't".

The experiences of the students with regard to assessment, underline the importance thereof as the first step in the nursing process. Thorough planning of effective patient care depends on the accurate and complete collection of data for analysis and decision-making with regard to nursing care (Viljoen, 1992:2). Due to the pressure of many clients to be screened by the students, the problem-oriented approach was followed. The information gathered relates to the present disease condition and how it compares with the previous health status, the patient's experience of the illness, what this means and what coping mechanisms are being used.

Services to the community are provided in accordance with National Health policies, programmes and guidelines of Namibia. The students were exposed to the management of some of these programmes within the context of the health clinic or centre. Activities were planned and managed in order to achieve objectives through the utilisation of physical and human resources (Searle, Brink \& Grobbelaar, 1992:597).

From the start all students were accepted as members of the health team. As one respondent said: "We could discuss health problems with the nurse management, consult- 
ing with the doctor, it made me feel part of the team here". Team management renders the opportunity to make the best use of the abilities of available staff members (Booyens, 1993:301). The health team members are used to assess clients, plan client care or services and manage quality improvement activities. Teams may include members of multiple health disciplines and from the community themselves (Stanhope and Lancaster, 2000:899).

\section{- Involvement with community activities/services \\ Outreach programmes}

Community-based health care is organised and facilitated from the health centre. All the respondents partake in this activity and was underlined by: "It was also good to go out into the outreach programmes to render services of immunisation, ante natal care, post natal care, treatment of tuberculosis clients and to detect new cases of tuberculosis".

\section{Cultural sensitivity}

The students also mentioned the development of sensitivity towards other cultures, values and beliefs. "I appreciated the outreach programmes because the Bushmen sometimes do not feel like coming to the clinic because of being too ill or due to travelling long distances", while another said "It was important to learn basic words of the local languages to make communication easier".

The involvement of community members in health is a primary health principle. The students' reactions to this were: "A good thing to experience was the involvement of the community in health matters. Some were trained in the prevention of malaria, tuberculosis and to be translators". "Community members who are employed are chosen to be representatives on the community committee while another member acted as secretary to the meeting".

When the authors reflected on the above descriptions, it almost appeared as though the students developed sensitivity towards the needs of people from different cultures. Other aspects that were suggested were trust building, respect, acceptance and honesty. Stanhope and Lancaster (2000:139) support these findings by stating that a nurse who cares for clients (individuals, families and communities) who are culturally different from him or herself will be able to apply strategies that are beneficial, appropriate and useful to the client.

\section{Negative experiences}

During their placement within the rural communities, the students experienced certain constraints. For example - feelings that expectations have not been met, being confused by nursing management activities and nursing practices as observed in the health centres and the realisation of a lack of health services to vulnerable groups in the community.

\section{- Self development}

\section{Expectations not being met}

Although the students were orientated towards the rural placement programme and pre-visits were paid to the respective health centres by the lecturers to orientated the district health management about the programme, a number of them described the uncertainty they had to deal with. Some of their comments were: "The nurses were not aware or did not know what was expected from them...", "the people were not expecting us and so nothing was prepared" and "I found it strange that the clinic staff seemed to be scared of us?" and "... the place was the opposite of what we were expecting".

\section{Frustrations experienced during daily practices}

The students commented they experienced frustrations that hampered their nursing practice. These were due to working long hours, dealing with the demands of clients, being doubted by the community of nursing care abilities, while the majority indicated frustration due to poor management of medications, stock and equipment in the health centres. As one stated: "... patients came anytime during the night, week days, week-ends, this really discouraged me to work at the clinic..." and "Some of the community members here however doubted us because they do not know these new nurses (kids) and do not want to be treated by us...". Other responses were "Prescribed medication is given in half doses and when we pointed out things done the wrong way we were told that we will realise how tough it is when we are registered! I view these as demoralisation and discouragement" and "Although I lay a complaint it just seems nothing changes" while another responded "No meetings are held to discuss issues of concern at the clinic".

\section{Lack of tutorial support}

A number of students expressed their frustrations of a lack of support and guidance by the lecturers as well as complaining about certain aspects in their practical register that were unclear to them. Responses to these statements were: "There are some points in our registers that are just very difficult to understand", and "... lecturers should visit us more regularly to guide us".

This rural placement programme within the revised curriculum of the Nursing Department, both the lecturers as facilitators of the programme and students as participants, find themselves in a new situation that was different Irom the traditional curriculum. This often led to feelings of frustration, tension, incompetence and scepticism among the role players (Fichardt \& Du Rand, 2000:7).

The community as a clinical learning environment promotes self-directed learning, as described by Quinn (1995:183-184). In preparation to this exercise, the student must be helped to become aware of his or her learning needs in order to become self-directing and initial pre-placement discussions are invaluable as a way of establishing a preliminary learning contract.

Frustrations and negative experiences with regard to their day-to-day practices stress the importance of decisionmaking with regards to the problems at hand. However, 
typical factors that influence decision-making of the students include the following: the mission of the health centre, the hierarchical structure of the health centre, the cultural and social sphere in which the centre operates, the economic climate within the larger organisation (Ministry of Health and Social services), the resources available and the main characteristics of the consumers of health care (Booyens, 1995:486).

\section{- Management of the health centre and nursing activities}

\section{Lack of proper client assessment}

Comments expressing student nurses' frustration with regard to client assessment were put forward: "Nurses here take meaningless and too short histories, probably due to work-overload" and make "unrealistic diagnosis and treatments" and "patients do not receive enough health education, especially during post-natal visits".

\section{Poor medication/drug and stock control}

Additional to the above-mentioned, the lack of prescribed medication and other stock necessary to treat patients contributed to their negative experiences. These experiences were expressed as follows: "It was like you know what to prescribe, but also knowing your first choice of treatment is out of stock!". "The ordering of medicine and stock is not done regularly and medicines usually run out of stock".

The following statement illustrates the aspect of poor medicine and stock control "The clinic pharmacy is not well stocked, cleaners have access to the pharmacy and drugs are not locked" and " ... chronic patients get treatment for 3-4 months without follow-up visits and paying any fees".

\section{Lack of support systems}

The health clinics are situated in the rural communities of each district. Thus, management of resources is of utmost importance. The lack of transport and other means of communication contributed to the frustrations and negative experiences of the students. "Another problem was transport, there is no ambulance at the clinic and it takes 3 hours to come for seriously sick patients".

Satisfaction in rendering a health service lies in good and appropriate planning. The best way to ensure success is to plan for it. Providing access to care, continuity of care that is affordable; personalised and interdisciplinary, should not be an accidental occurrence. Smith (1999:48) stated that role implementation of nurses moving into practice settings without preparation, is often stereotypical rather than progressive and dynamic. Professional practice should be knowledgeable, competent, thoughtful, creative and built on an educational foundation.

\section{- Awareness of vulnerable community groups/members}

The written descriptions indicated an awareness of the vulnerability of community members due to a lack of health services as well as harmful practices, practised within the community that may affect their health.

Some comments were: "Girls as young as 12 years are sent by their parents to the clinic to be injected without a proper knowledge of - why they need family planning?".

and " the young tend to abuse alcohol due to an increase of bars and bottle stores in the community" while "there is an increase of school drop outs due to teenage pregnancy and poverty" and "some problems are commonly seen in communities and they regard that as normal". Specific reference towards disabled people as a vulnerable group was mentioned by the respondents and health services towards these groups were experienced as follows: "... some of them have to stay a long time without their equipment for example, urine bags, catheters".

Exposure to the communities in rural areas brought to light the vast range of social and health problems. It seems to the authors that the students became more aware of cultural perceptions with regard to health issues and that health knowledge still lack among community members. This experience may reverberate within a statement made by one of the students "It was a horrible experience to go to the community and look at all the poverty and malnutrition among the children".

Although sometimes with a result of negative experiences, Stanhope and Lancaster (2000:143-144) emphasise the necessity for nurses to develop an appreciation of, and sensitivity to clients' values, beliefs, practices, lifestyles and problem-solving strategies. This implies that nurses are receptive to learning about the cultural dimensions of the client, but also to examine his or her own personal values and biases. Nurses, who are culturally aware, understand the basis for their own behaviour and how it helps or hinders the delivery of competent care to persons from cultures other than their own

\section{Suggestions}

An overwhelming response was received for the continuation of the rural placement programme. The majority of student nurses felt that the arrangements around and organisation of the rural placement programme was satisfactory.

As one respondent summarised his experience "This was really a good experience. I leamed to be self-confident, walking on my own, manage health problems. I think students need to be placed at the rural clinics every year....".

Some recommend a longer period "I would suggest that the two months be extended to three" while others stated, "two months are too long, and we lag behind with our lectures".

A suggestion that continuous involvement of lecturers is necessary was supported by "lecturers have to go and give lectures to students while in rural placement, to prevent content delay and this helps in time management " and "we loose too much time with regard to theoretical 
work" and this could help management to be strengthened through regular contact with the lecturers.

The structural organisation of the programme could be looked into. Recommendations made by the nursing students were as follows: " it will be better if the supervisor of the clinics be equipped and orientated on what is expected from them during the placement" and "you have to negotiate with the Ministry for the students to get some pocket money because the shops available are too expensive".

A number of students recommended in-service training for health staff in the rural clinics in order to up-date them on current health issues. "Nurses need to be trained in full history taking, prescription of medicine, ordering of drugs and materials as well as in the area of management, supervision and control".

A recommendation pertaining the practical register stated "something should be done about the register, especially community health and ethos that was very difficult to understand".

It should be noted that although students in a rural placement programme are expected to be self-directed, they still need some supervision, guidance and support with managing their learning activities. Dana \& Gwele (1998:63) argued that the need to balance supervision with self-directed learning may take some time to develop in a profession that traditionally saw the nursing students as totally dependent in terms of teaching and learning activities. Lecturers as facilitators in community clinical settings will have to learn to strike a balance between direction and guidance.

\section{Discussion}

The article highlights the importance of the community as an effective learning environment for students, but also shows that opportunities for learning should be chosen with care and supportive by sufficient resources. Development of the student's ability to solve health and health related problems, lead to confidence and satisfaction with his/her role as promoter of health, manager of problems and a resource person within the multi-disciplinary health team.

Despite the negative experiences, it came out clear that the students have gained confidence in problem management as experienced in the community. Being exposed to the communitie's own settings helped the students to appreciate the health problems they encounter at health facilities. It is our belief that students have gained an understanding of the complexity of various factors that could affect their clients in relation to their health problems. The suggestions made by the students have to be considered during the planning of placement programmes for the future.

\section{Conclusion}

The rural placement programme was an educational and good experience for both the students and lecturers. Careful planning and a strong support system should be put in place to ensure maximum application of Primary Health care/ community based care in future placement programmes. The process helped the nursing students to grow and develop self confidence in their work as they tackle problems on their own without doctors and or registered nurses.

\section{References}

BOOYENS, SW (ED) 1993: Dimensions of Nursing Management. Juta: Kenwyn.

BURNS, N \& GROVE, SK 1997: The practice of nursing research. $3^{\text {rd }}$ edition. Philadelphia, PA: Saunders.

CRESWELL, JW 1994: Research design: qualitative and quantitative approaches. Thousand Oaks, California: Sage.

DANA, N \& GWELE, NS 1998: Perceptions of student nurses of their personal and academic development during placement in the community as a clinical environment. Curationis. March 1998, 58-64.

ERKEL, EA; NIVENS, AS \& KENNEDY, DA 1995: Intensive immersion of nursing students in rural interdisciplinary care. Journal of Nursing Education. 34(8): 359-365.

FALLER, HS; DOWELL, MA \& JACKSON, MA 1995: Bridge to the future: non-traditional clinical settings, concepts and issues. Journal of Nursing Education, 34 (8):344349 .

FICHARDT EF \& DU RAND PP 2000: Facilitators' perceptions of problem-based learning and community-based education. Health SA Gesondheid. 5(2) July 2000:3-10.

LINCOLN, YS \& GUBA, EG 1985: Naturalistic enquiry. Beverly Hills: Sage.

MORSE, JM \& FIELD, PA 1996: Nursing research. The Application of Qualitative Approaches. Chapman and Hall: London.

NOORMAN, ZM 1994: Implementation of a communityoriented curriculum: The task and the problems. Vlllth International workshop on Community-based education incorporating problem-based learning. March, 21-27. Egypt: Ismalia.

ONEHA. MF; MAGNUSSENL \& FELETTI. G 1998: Nurse Educator. 23(1): 26-31.

PETERS, RM 1995: Teaching Population-Focused practice to Baccalaureate Nursing Students: A Clinical model. Journal of Nursing Education. 34(8): 378-383.

QUINN, FM 1995: The principles and Practice of Nurse Education. $3^{\text {rd }}$ edition. Stanley Thornes: London.

REILLY, DE \& OERMANN, MH 1985: The clinical field, its 
use in nursing education. Norwalk: Appleton-Century Crofts.

SEARLE, C; BRINK, HIL \& GROBBELAAR, WC 1992: Aspects of community Health. King Edward VII Trust: Cape Town.

SMITH, R. 1999: Ambulatory Care Nursing Courses. Nurse Educator, 24(4): 45-48.

STANHOPE, M. \& LANCASTER, J 2000: Community \& Public Health Nursing. $5^{\text {th }}$ edition. Mosby: St. Louis.

TENN, L. 1995: Primary health care nursing education in Canadian university school of nursing. Journal of Nursing Education. 24(8): 350-357.

VILJOEN, MJ 1992: Nursing assessment: History-Taking and the Physical Examination. Haum: Pretoria.

WORLD HEALTH ORGANISATION (WHO) 1985:

Community-based education of health personnel. Geneva, 4-6 November: 5-87. 